DOI: 10.2478 /ausfm-2014-0011

\title{
Thinking Like a Carpet: Embodied Perception and Individuation in Algorithmic Media
}

\author{
Laura U. Marks \\ Simon Fraser University, Vancouver \\ E-mail: lmarks@sfu.ca
}

\begin{abstract}
Keynote talk given at the "Cinema of Sensations” International Conference organized by the Sapientia Hungarian University of Transylvania, in Cluj-Napoca, Romania, between the $25^{\text {th }}$ and $27^{\text {th }}$ of May, 2012. (The photos of Laura Marks illustrating the article were taken by Dorel Găină, and are reproduced here with the permission of the artist.) ${ }^{1}$
\end{abstract}

Keywords: embodied perception, algorithimic media, Deleuze, carpet as machinic phylum.
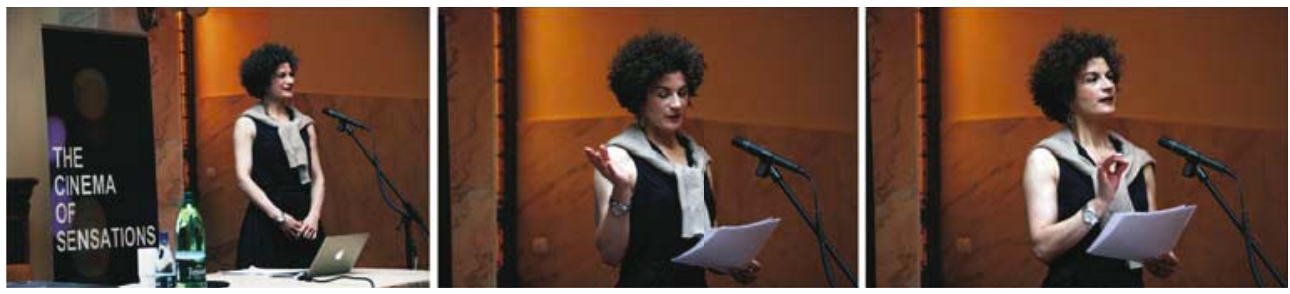

I have been slowly returning to cinema from long visit to Islamic art and philosophy: Enfoldment and Infinity. There I learned: once you suspend figurative image making, a world of creativity opens up. Large-scale forms, such as figures and narrative, cramp the creative energy of the lines and colors that compose them. But as you know, Islamic art is often aniconic. Freed from representing figures, its lines and forms take on a life of their own. Figures are molar, but life is molecular. So I propose thinking like a carpet as a way to release the life contained by figures.

Is it possible to release the energy contained in small units, instead of making them conform to human-scale forms? What would it be to inhabit the point of view of a point?

1 A similar but divergent essay appears in Entautomatisierung [Deautomatization], ed. Annette Beauerhoch, Norbert Otto Eke, Renate Weiser, and Anke Zechner (Paderborn: University of Padereborn Press, 2013). 
Thinking like a carpet can be a way to start at any point and connect to the universe. A way to unleash creative energy that's not available when we start at a larger scale. What I'm after is not only the thoughts and hands of weavers as they produce these astonishing patterns. It's not only the material of wool and silk, or for that matter of pixels and silicon in new carpet-like media. It's the way the carpet itself thinks, pulling forces from the weavers, the yarns, the matrix, the algorithm and producing something new: the carpet as a force of individuation.

In my book, Enfoldment and Infinity (2010), I compared the media art of our time to the religious art of Islam. I was inspired by Islamic art and Islamic thought because, in avoiding a direct representation of God, they create powerful abstractions that indicate the divine presence/absence, are pulled toward it, demonstrate and perform it, but do not show it. This power of non-representation created the conditions of a kind of nonorganic life in Islamic art.

Enfoldment and Infinity ended by going beyond religion. In the last chapter I looked at some carpets that seem to have an internal life force that does not obey the injunctions of a benevolent (or any other kind of) God; carpets that suggest we do not need to ascribe creation to God because Life creates itself. This talk develops on that perception:

1. life of points

2. points connect to the universe

3. algorithmic media (carpets)

4. ways different kinds of carpets imagine the universe

5. carpet as machinic phylum

6. embodied response

I propose to examine the ways non-figurative, or aniconic images may appeal to an embodied way of looking that gets out of a human perspective and into the perspective of a point.

\section{Aniconism}

There are many reasons why Islamic religious art tends to be aniconic. Islam came about at a time when the other religions of the book, Judaism and Christianity, were iconoclastic. Aniconism helped distinguish Islam from other religions visually. The Qur'an cautions humans not to compete with God by trying to make living forms, and that it is impossible to conceive of God. God, being beyond comprehension, is also beyond representation. A branch of rationalist philosophers of ninth-century Iraq, called the Mu'tazili, argued that since God is indivisible, He has no attributes 
(such as sitting on a throne). Thus any attempt to identify the properties of God in art risks blasphemy (see Tarif Khalidi [1985], 84). Theirs was not the only view, and I must note that in the eastern Muslim world, dominated by Shi'ite Islam, there exist many figurative images of Muhammad and other saintly people - images that would be cause for persecution in the western, largely Sunni, Muslim world. Still, Islamic art for religious reasons almost always avoids depicting anything with a face, anything with a body, and even sometimes anything with an outline. It is an abstract religious art that shifts your attention away from the human scale and both out toward the infinitely large and in toward the very small.

\section{The Interval: Perception of a Point}

Looking at a carpet, entering its patterns from any point, our perception creates something new. The idea that perception must discover the world anew every time arose in the thought of the scientist of optics Abu'Ali al-Hassan Ibn al-Haytham (b. Basra 965, d. Cairo 1039), known in the West as Alhazen. Ibn al-Haytham introduced the intromission theory of vision in his Kitab al-Manazir or Treatise on Optics around 1000. Consulted in Arabic, and translated into Latin in 1200 by Gerard of Cremona (see Ahmad 1969, 37), the Optics remained the major work on optics until Kepler in the seventeenth century (see Lindberg 1976, 58-60). In it Ibn al-Haytham described a contemplative mode of perception. He argued that we do not automatically perceive form; form is a psychological concept, not a given in nature. This means that contemplation is necessary for the recognition of form, for it requires us to use our internal faculties, such as memory, comparison, imagination, and judgment. Ascertainment can only be relative, to the limits of sense perception (see Sabra 1994, 170-171). So form is produced in an oscillation between what we see and mental operations: it is created in time, in the embodied mind.

In Enfoldment and Infinity I noted the remarkable similarity between alHaytham's theory of perception and that of Henri Bergson, 900 years later. Bergson's concept of the subject as a center of indetermination influenced Gilles Deleuze's Leibnizian idea that perception does not reproduce the world but unfolds it from its particular point of view. We humans, like other creatures, tend to act on our perceptions (we see food, smell danger, etc.). But, as Bergson argued, the wider the interval between perception and action - the more time you absorb the perceived world from your given perspective - the more of the universe you can perceive. The longer you look, the more you see (hear, smell, taste, etc.). Widening the interval requires undermining our creatural habits of perception- 
action. The wild boar seems to be attacking you, and instead of throwing your spear you take time to contemplate its fur, its tusks.... We might observe that widening the interval is in a certain way anti-human, for our basic human needs demand us to act decisively in order to preserve and sustain ourselves. Yet Ibn alHaytham's conception of perception, like Bergson's, proposed that human beings have a necessary leisure to contemplate what we perceive before we can act on it.

By shifting activity to a smaller scale, aniconic art (and aniconic ways of perceiving) widens the interval. Aniconism liberates the molecular from the molar, another paired term from Deleuze and Guattari that reflects the scientific proportion 1 mole $=10^{23}$ units. While the molar scale deals with large-scale happenings and general states, the molecular scale deals with tiny events, bursts of energy that we don't experience when we are acting at the molecular level.

So in privileging a non-human perspective we move not to a larger, God-like perspective, but to a tiny perspective: the point of view of a molecule. Or, say, an atom.

In Iraq in the $8^{\text {th }}$ and $9^{\text {th }}$ centuries, the Islamic atomist occasionalists, a group of the Mu'tazili rationalist theologians, argued that God was so powerful that no thing could endure except by His grace. The Mu'tazili argued that the world is composed of disconnected atoms and the accidents that befall them; and that rational inquiry can demonstrate how divine will causes atoms and accidents to come into existence and cease to exist. Later a conservative, mystical atomism (associated with al-Ash'ari and al-Ghazzali) asserted that humans cannot inquire into divine will and must instead submit to the random actions of the atomistic universe. God alone knows. Therefore, a body's tendency to hang together, to cohere, was simply an accident that befell its atoms. Those atoms could just as easily go their separate ways.

Lenn Evan Goodman describes their argument thus: "No substance extends beyond a point, for the givenness of one point of being does not imply that of another, ... lest we limit God's omnipotence and the fundamental datum of contingency." Furthermore, "To the radicals of the kalâm [rationalist theologicans] this meant that God might create intelligence in an atom, or in no substrate at all, without the prerequisite of, say, Life" (Goodman 1992, 53). Here already is a sort of declaration of independence of points, of atoms: independent of each other, but not of course of God's will. The kalâm atomists prefigured a molecular life disdainful of molar habits - though of course all this was only to defer to God's freedom to reorganize the world, atom by atom, as He might see fit.

Writing on Greek atomism, Deleuze and Guattari observe, "The ancient atom is entirely misunderstood if it is overlooked that its essence is to course and flow." An aggregate of atoms, they write, is a war machine, "a physics of packs, 
turbulences, 'catastrophes,' and epidemics” (Deleuze and Guattari 1987, 489, 490). Atoms are not obedient to form but flow in smooth space, coalescing in all kinds of intensive ways. ${ }^{2}$

We hear from such free particles a couple of times in The Movement-Image when Deleuze describes how the smallest elements of "flowing-matter" are perceiving, acting; alive. We do not need to see things, for things themselves already see: "The eye is in things," he writes, referring to Bergson, who imagined that every point has a point of view that can be, as it were, photographed: "taken in the interior of things and for all the points of space" (Deleuze 1986, 60). These kinds of photographs taken from inside particles are now cropping up in scientific imaging. Similarly, Deleuze identified a gaseous perception in the films of Dziga Vertov, American experimental cinema, and video (we might think of the analog video synthesis of Eric Siegel): works that do not connect movements together but privilege the energy of each freely moving particle. They attain "a pure perception, as it is in things or in matter, to the point to which molecular interactions extend." Gaseous perception, then, achieves the radical openness to the universe implicit in Bergson's philosophy of perception: the interval between perception and action becomes so minute that the particle's entire existence consists of perceiving and acting in a single instant.
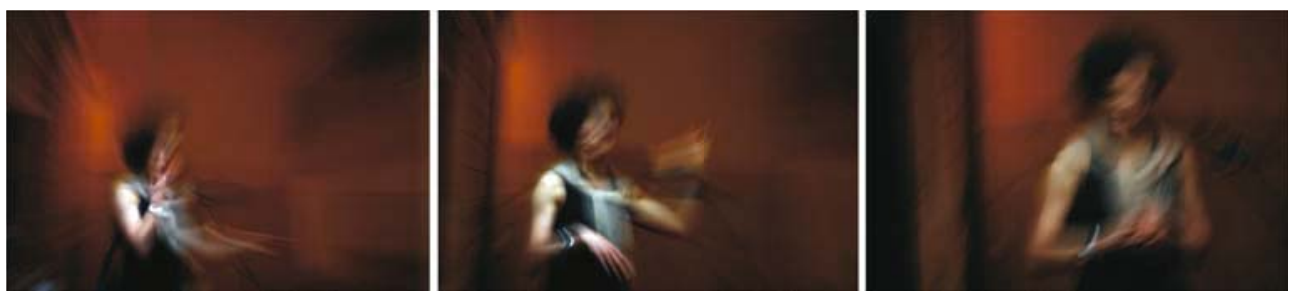

Deleuze thus attributes life to the tiniest particles of matter. This theme occurs also in The Fold, where Deleuze extends Leibniz's already generous definition of the soul, or the monad, from organic entities to anything that "perceives," i.e. discriminates among and reacts to its environment. Thus cells, proteins, molecules, photons, and atoms can all be considered to perceive. The universe swarms with infinitesimal souls! This attribution of life to all entities calls to mind Charles Peirce's statement, "Viewing a thing from the outside, considering its relations of action and reaction with other things, it appears as matter. Viewing

2 "Smooth space" refers to space that is heterogeneous and intensively organized; "striated space" refers to territory that is homogeneous and subject to general laws (Deleuze and Guattari 1987, 474-500). 
it from the inside, looking at its immediate character as feeling, it appears as consciousness" (Peirce 1935, 268).

The Deleuzian film theorist Elena Del Rio argues that a film (or, we can extrapolate, any artwork) often takes place on the dueling levels of molar/ molecular: large scale/small scale, representation/hundreds of small events. The molar level of meaning, values, narrative may say one thing; the molecular level (affects, attractions) another (see Del Rio 2008, 26-55). Del Rio, analyzing the melodramas of Douglas Sirk, points out that while the narrative takes place on a molar level, trying to convince the audience into ideological beliefs such as the productive Oedipal family, on the molecular level a completely different kind of energy acts. Del Rio describes the "bad girl" character Marylee in Sirk's Written on the Wind: she's sexually voracious and frustrated - a "tramp" - wears hot colors, bubbles with swishy, provocative gestures, loves music, loves to dance. Marylee is a mass of molecular energy who cannot be contained by the molar morality of the film's plot. Del Rio argues that representation is molar, performance is molecular. Representation re-presents, it's stuck with the precedent. Performance creates something new: becoming. Marylee is alive with an energy that bursts the bounds of representation - like a carpet.

Figure 1. Screenshots from Douglas Sirk's Written on the Wind
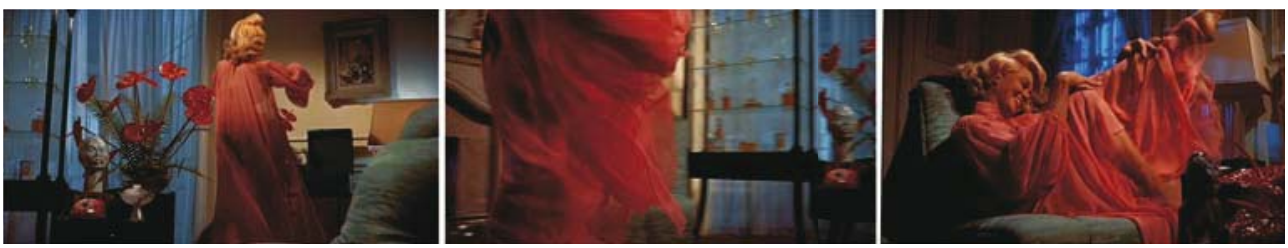

\section{Points Connected to the Universe}

So we have a conception of the universe as a swirl of lifelike particles, a dance of points. From an atomist perspective, the points are disconnected. But if we consider the universe to be a plenum, a space entirely filled with matter, points are the seemingly disconnected surface of an internally connected substance. Deleuze in The Fold argues the latter: all matter and spirit are inseparable, one fabric, deeply folded. What look like points are really the inflection points of folds (Deleuze 1993, 16). The fabric of the universe is matter; the powers that fold it from the inside are spirit. As Mario Perniola writes (1995, 3-21), the world is not empty, it's full: so full that everything has to be folded up to fit. 
The Baroque paintings of El Greco interested Deleuze for the way they depict the universe as a field of folds. El Greco's harsh white highlights and slashing dark crevices emphasize the folded texture of matter. The tips of these folds look to us like points, but if you take one and drag it out you unfold a section of the universe. Certain parts of the image bulge out toward us, others remain hidden. In El Greco's Annunciation at the Prado, some of the universe remains enfolded, like the vague area behind the dove or holy spirit that flies down between clouds, the squashed-together mass of angel musicians, and the deep folds of Mary's robe. This is because heaven and earth are on the same plane, a deep fold between them.

The accordion-like space in El Greco also suggests we could unfold it in the opposite direction, the peaks becoming valleys and the valleys, peaks. It gives a sense that not everything is available to vision, but rather it is a struggle to make things perceptible, to unfold the world to perception. The composition tips and tilts: it does not offer the scene to one privileged viewing position, as in Renaissance perspective, but inflects at certain points (as Deleuze writes, calling upon Leibniz's calculus-based conception of the universe), emphasizing that the universe appears differently to every point of view. This point of view is, of course, the perspective of the monad, Leibniz's soul that perceives the entire universe from its limited perspective. The monad is a kind of dependent universe (Deleuze 1993, 53).

Reading the Monadology you perceive that the religious premise underlying Leibniz's folded universe causes it (as in much Islamic thought) to be closed in on itself. Nothing is free in this universe except for God: this is because Leibniz needs to guarantee the liberty of the deity at the expense of His creatures. God even foreordains the amplitude of the soul, i.e. whether the soul will be saved or damned (Deleuze 1993, 71). Thus we encounter in religious thought a universe that is not really free because it is subject to the freedom of God. Deleuze overturns this almost casually in The Fold, asserting that in modern thought an open universe replaced the closed one and Process has replaced God. Yet he retains the powerful model of a universe connected by folds, in which a single source can individuate infinitely.

The Fold, in short, attributes a capacity for life to non-organic things: molecules, atoms, points of matter. Furthermore, it suggests that these points an intensive perception, freed from anthromorphic perspective, that connect them to the very source of life. So we get a sense that the universe appears as a series of disconnected points that are, in fact, all connected by folds. If we can relinquish a human point of view for a while, we can enter into the perception of these points, 
perceive the universe the way a point, a molecule, an atom might perceive it. An infinity of dispersed, tiny points of view that connect us to the universe.

\section{Carpets as Algorithmic Media}

All carpets have some degree of automatization: the square matrix of the loom, determination of number of threads per inch, knot style, and design. Given their basis in calculation, carpets are a fundamentally algorithmic medium, where an algorithm is an instruction to be executed. It's important to note that carpet designs are not necessarily determined by the materiality of their medium. Many carpets borrow their designs from other media, such as painting. So the algorithms that carpets carry out are somewhat independent of the medium. Carpets don't only express the material, they express a relationship between material and idea: an algorithm.

We can say carpets index their algorithms, for examining a carpet we can figure out the algorithms followed by the weaver (Soderman 2007). For example, the pattern of the Lotto carpet (so called because it occurs in the paintings of Lorenzo Lotto) applies algorithms of recursion and mirroring to basic motifs in order to fill a field with them. And, thinking in an unfolding way, we can say those algorithms in turn index their weavers, designers, and programmers. Looking at them we see the expression of the instructions for their making, a communication between the designer and the weaver.

Algorithms are created by humans, of course, so far from being a cold impersonal medium, algorithmic works like carpets indicate all kinds of decision-making, reflection, even emotion - and of course error. For example, a carpet in the collection that Joseph McMullen amassed in the early decades of the twentieth century and donated to the Metropolitan Museum of Art in New York, allows us both to image the model (the algorithm) that the weaver followed and to intuit the decisions she made that deviate from themodel in executing it. It is a funny-looking carpet with asymmetrical touches of color. The collector described it this way: "This is a very close but hilarious descendant of no. 97 [another carpet in the collection].... The design is basically faithful.... But there is no comparison between the sloppy drawing in this rug and the sophistication of its model, while the use, or misuse, of colour, particularly blue in the central medallion, is strange indeed, without system or sense. Again green is used in the corner pieces at one end only. It is all a refreshing reminder that the human spirit can, and does, produce wonderful effects impossible to the trained and sophisticated mind.” (Joseph McMullan 1972, 52.) 
Algorithmic media, when executed by hand, permits all kinds of decisions, felicities, and mistakes to occur. But what about algorithmic media executed by machines, such as computers? I shall return to this question.
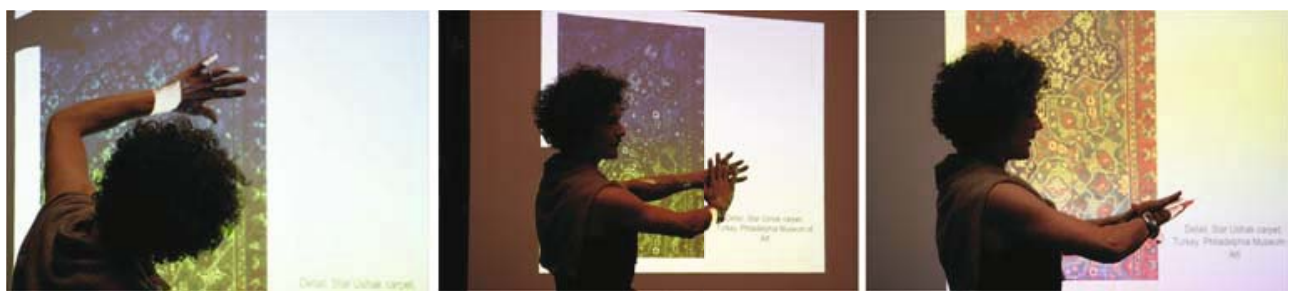

\section{Carpets Imagine the Universe}

Art historians sometimes interpret carpet designs as models of the universe, and I have adopted this slightly old-fashioned practice. For example, a number of Persian carpets look a bit like a universe in which everything emanates from God, as in Islamic Neoplatonism. From a central medallion radiate patterns that become ever more complex: sometimes their motifs are entirely abstract, sometimes they are floral, and sometimes their vinelike forms intertwine tiny creatures. The most complex such carpets were woven during the Safavid period, 1501-1732. They imply a relationship between infinitesimal and infinite, for from any point of view you can reconstitute the generating center, as the monad reconstitutes the universe from its point of view. Ultimately they confirm a whole, though, because the individual motifs do not make sense independently of the center that gives rise to them.

A set of Turkish carpet designs from Ottoman times, such as the Ushak carpets, consist of medallions (symmetrical radiating shapes) inside medallions in contrasting colors, each with a complex, intertwining pattern, set against a ground whose pattern is similarly complex. These carpets depict a mise-en-abîme of worlds within worlds. Carpet scholars sometimes suggest that the center or the deepest layer represents heaven; often the motifs become increasingly refined as they approach the "divine" center. A mystical view could see these carpets as lessons that all of reality is illusory, but that the universe has an underlying Structure.

Another group of carpets begin to set their patterns free from central organization and permit independence to their individual motifs. These are Caucasian carpets, woven in the seventeenth and eighteenth centuries in the Caucasus (a region at the time loosely politically organized but with basic allegiance to Iran). In Caucasian 
carpets life seems to begin not from a Center but from the smallest point, from any point whatever: it self-organizes, mutates. The oddness and particularity of the forms in Caucasian carpets suggests they each evolved in their own way. In the final chapter of Enfoldment and Infinity I compare Caucasian carpets to generative algorithms, algorithms that respond to new information and come up with results that could not be prefigured in the algorithm's initial state.

\section{Material Algorithms: Carpet as Machinic Phyla}

So carpets figure the universe. But even the most strictly ordered, hierarchical carpets produce singularities where idea meets matter. No two motifs can be exactly the same when they are executed on a loom with a certain thread count, with wool or silk of a certain diameter, by hands of weavers with varying skills and interests. My favorite example is the medallion and star carpet, Eastern Anatolia, 16th-17th century, from the Ulu Mosque of Divrigi-Sivas, now in the Vakiflar Carpet Museum, Istanbul. Each floral motif, boxy arabesque, and (Chinese-derived) cloud band is different from the others. Unlike the carpets I described above, these motifs do not seem to emanate from the center, a stiff little blue medallion. They refuse to be subordinated to the "transcendental" center, as though they've heard of heaven and they want none of it! This carpet insists that there is something in material that resists idealism, that has its own ideas of how to develop. It reminds us that matter to be formed has "an entire energetic materiality in movement, carrying singularities or haeccities that are already like implicit forms that are topological, rather than geometrical, and that combine with the forces of deformation: for example, the variable undulations and torsions of the fibers guiding the operation of splitting wood," together with variable intensive effects, such as porosity and resistance (Deleuze and Guattari 1987, 408-409). A carpet, arising from the meeting of ideas (designs, algorithms) and matter in the hands of the weaver, is a machinic phylum: "materiality, natural or artificial, and both simultaneously; it is matter in movement, in flux, in variation, matter as a conveyor of singularities" (Deleuze and Guattari 1987, 409). ${ }^{3}$ The weavers have to follow the material and let its singularities guide their hands; yet they are also introducing (not imposing) ideas to material, and rolling matter and idea together in forms that will be slightly different each time.

3 In The Fold Deleuze characterizes Leibniz's third order of infinity as an intensive series of qualities that are possible but not necessary, which constitute "the real in matter: texture of a substance, timbre of a sound, malleability of gold, etc. $(1993,47)$. If the world is included in the soul, the monad, it is creased in matter $(1993,102)$. 


\section{Embodied Response}

What does contemplating these patterns do to our bodies? On the one hand, it enlarges us. We are wired to perceive pattern, for pattern makes order out of a chaotic universe. Our brains look for patterns in images with low information content. ${ }^{4}$ Our brains are constituted to seek order; they create order out of chaos. Our brains protect us from meaninglessness.

So it seems that the patterns of carpets confirms the certainty of embodied subjectivity, by giving us pattern where we look for it. A phenomenological view suggests that engaging with a carpet enlarges our capacity for perception.

I suggest all carpets appeal to an embodied response at levels from the molar to the molecular.

Some carpets invite an identification with figure and narrative, just as movies do. Some Safavid Persian carpets take advantage of extremely high thread counts (or pixels) to depict delightful scenes borrowed from paintings of people hunting, playing music, and relaxing in gardens, as well as all kinds of animals. As much as a Douglas Sirk film, these carpets invite a narrative identification with figures, which operates on a molar level.

Some carpets even command an acknowledgment of social hierarchy: we see this in carpets with heraldic symbols woven by Muslims in Spain in the fifteenth century for Castilian nobility. Yet these carpets undermine hierarchy by imbuing the fields of floral and geometric motifs under the heraldic shields with subtle liveliness and framing the whole with quasi-Arabic writing.

Carpets can also invite us to identify with the riotous, fecund life of plants, as in the so-called vase carpets of Safavid Persia. ${ }^{5}$

Moving from a molar to a more molecular level, "below" figurative and symbolic images, we encouter carpets that appear entirely abstract, populated by lines that curve languidly and twist together smartly, by jagged, energetic lines, and by oscillating relationships of figure and ground. Feeling along with these forms we (I, anyway) find that the abstract pattern of a carpet itself appeals to shared embodiment. We could call this relationship empathy, in the term of turn-of20th-century theorists Theodor Lipps and Wilhelm Worringer for an "enjoyment of the self projected into a body or form:" suggesting that people "empathize" with abstract forms insofar as those forms undergo experiences that we too might

4 Patricia Pisters 2009, 224-240. Pisters refers to C. Bach and M. Poloschek, "Optical Illusions," Advances in Clinical Neuroscience and Rehabilitation 6: 2 (2006): 20-21.

5 I describe these at length in Chapter 10 of Enfoldment and Infinity (2010). 
undergo (cf. Morgan 1996, 317-341). We can relate to a line, feel the way a line feels. Thus thinking like a carpet invites experiments in corporeal perception. Where figuration invites identification through the comparison of the body beheld with one's own body, ornament appeals to a different kind of embodied relationship. We can even feel along with the expressive rhythms of line in space, as in the wonderfully "independent" carpet from the Ulu Mosque discussed above.

The above is a phenomenological view, which I like a lot. It argues that abstract pattern appeals to our bodies: perhaps to confirm the embodiment that we already have, but also, I think, to gently expand it and invite us to take on new kinds of embodiment. However, as we shift from a molar to a molecular level, we may also find that pattern does not confirm what we already are; rather it undoes our bodies' usual ways of being. This is especially so because pattern appeals to rhythm. Rhythm unmakes and remakes the body - as in Written on the Wind, when the "bad" daughter Marylee dances with such energy that she "causes" her father to fall to his death on the stairs.

Here I look to Deleuze again, on rhythm. Deleuze argues in Francis Bacon: The Logic of Sensation that representation speaks to cognition, confirming what we already know. But the kind of image he calls the Figural bypasses the mind to appeal directly to the nervous system. Deleuze holds out for the nervous system as the one site in our body that is not colonized by clichés. Perception itself is already informed by habit and social custom: this is where Deleuze parts company with phenomenology. Sensation, attacking the nervous system directly, is the only way we can feel something that does not address "us" as already formed. Thus the figural does not address the body we already have, but makes us a new body.

Are the non-figurative patterns of carpets and other designs in Islamic art capable of seizing our nervous system? At first it seems the answer is no, because Deleuze doesn't find the Figural in forms that are non-figurative to begin with, such as the arabesque, geometric, and other symmetrical patterns of carpets. It would seem such patterns only achieve the "mathematical sublime." (See the discussion in Chapter Seven of Enfoldment and Infinity [2010].)

The violence of the Figural lies in the way it approaches conventional embodiment and then radically departs from it, taking the viewer's normal conception of embodied being with it. You can see the violence of the figural in the bizarre not-quite-creatures of Caucasian dragon carpets, which rear their stringy heads in Chapter Ten of Enfoldment and Infinity.

But does the Figural have to come as an assault? J.M. Bernstein finds the Figural in the colourful and schematic figure paintings of Matisse (2008, 37-55). But 
Bernstein finds a violence in Matisse's paintings in that they disembody the image, decreasing the corporealization of figures while increasing the corporealization of the painting as a whole (Bernstein 2008, 49). Matisse liberates the line, giving it "an uncanny expressive vitality of its own," independent of figuration - which is the power Deleuze and Guattari attributed to the abstract line. And as we know, Islamic carpets profoundly inspired Matisse's search for patterns that would envelop the figure and absorb it.

I think we should attribute the power of the Figural to the non-figurative, or not-quite-figurative, patterns that invaded Western painting from the East. Islamic aesthetics were the undoing of European figurative art. The uneasiness of the Figural often results directly from a confrontation of a molar-scale, figurative image with the rhythmic energy of the abstract line. ${ }^{6}$ Whether the carpets themselves are Figural probably lines in whether a person comes to them with a figurative mindset in the first place. Someone accustomed to figurative images may encounter a Figural shock; someone who has spent more time surrounded by non-figurative images is less likely to.

Thus our bodies can indeed respond to non-figurative works, like carpets, with shock and a feeling of coming undone. We may feel ourselves being rearranged, becoming less molar and more molecular; we may feel ourselves as masses of living points that connect to the entire universe. We may find ourselves thinking like a carpet.

\section{Conclusion}

Might thinking like a carpet offer a model of ethical being? If so, it would be a mode of being that keeps on changing, powered by a force that, while coming from within, exceeds the bounds of the individual. This is what Deleuze was after in his final writing, A Life. Is it too much of a leap to hold up this process of perpetual individuation as a model of political organization? John Rachjman writes, "We should judge political regimes (including democratic ones) in terms of the space they allow for 'multiplicities' and their 'individuations' - for the time of 'a life"” $(2000,82)$. Modestly I would like to suggest that thinking like a carpet may help us model, with our thoughts and our bodies, the relationships between points and the universe; and it may give us some courage for the tranformations that being open to the universe will bring.

6 Chapters Three and Four of Enfoldment and Infinity (2010) examine in detail this "invasion" of Islamc aesthetics into Western art from the thirteenth to the nineteenth centuries. 


\section{References}

Ahmad, Nazir. 1969. Ibn Al-Haitham: His Life and Work. In Ibn Al-Haitham, ed. Hakim Mohammad Said. Karachi: Hamdard National Foundation.

Bernstein, J.M. 2008. In Praise of Pure Violence (Matisse's War). In The Life and Death of Images: Ethics and Aesthetics, ed. Diarmuid Costello and Dominic Willsdon, 37-55. Ithaca: Cornell University Press.

Deleuze, Gilles. 1986. Cinema 1: The Movement-Image. Minneapolis: Minnesota UP.

Deleuze, Gilles. 1993. The Fold: Leibniz and the Baroque. Minneapolis: Minnesota UP.

Deleuze, Gilles and Félix Guattari. 1987. A Thousand Plateaus: Capitalism and Schizophrenia. Minneapolis: Minnesota University Press.

Del Rio, Elena. 2008. Deleuze and the Cinemas of Performance: Powers of Affection. Edinburgh University Press.

Goodman, Lenn Evan. 1992. Avicenna. New York: Routledge.

Khalidi, Tarif. 1985. Classical Arab Islam: The Heritage and Culture of the Golden Age. Princeton: Darwin.

Lindberg, David C. 1976. Theories of Vision from Al-Kindi to Kepler. University of Chicago.

Marks, Laura U. 2010. Enfoldment and Infinity: An Islamic Genealogy of New Media Art. Cambridge. MA: MIT Press.

Morgan, David. 1996. The Idea of Abstraction in German Theories of the Ornament from Kant to Kandinsky. Journal of the History of Ideas vol. 57 no. 2: 317-341.

Peirce, Charles Sanders. 1935. Man’s Glassy Essence. In Collected Papers 6, eds. Charles Hartshorne and Paul Weiss, 155-175. Cambridge, MA: Harvard University Press.

Perniola, Mario. 1995. Secrets, Folds, and Enigmas. In Enigmas: The Egyptian Moment in Society and Art. London: Verso.

Pisters, Patricia. 2009. Illusionary Perception and Cinema: Experimental Thoughts on Film Theory and Neuroscience. In Deleuze and New Technology, eds. Mark Poster and David Savat, 224-240. Edinburgh: Edinburgh University Press.

Rachjmann, John. 2000. Deleuze Connections. Cambridge, MA: MIT Press.

Sabra, A. I. 1994. Optics, Astronomy, and Logic: Studies in Arabic Science and Philosophy. Aldershot, UK: Variorum.

Soderman, Braxton. 2007. The Index and the Algorithm. Differences vol. 18 no. 1: 153-186. 